\title{
Retail Seafood Waste Prevention: Reducing Retail and Consumer Fresh-Fish Waste by Cooking Directly from Frozen
}

\author{
Thomas 0’Donnell1, Solomon H. Katz², Alexandra Romey³, Benjamin Fulton4, Linda Croskey, \\ Pete Pearson ${ }^{5}$, Jonathan Deutsch ${ }^{4}$
}

${ }^{1}$ Land, Chemicals, and Redevelopment Division, U.S. Environmental Protection Agency, Philadelphia, PA, USA

${ }^{2}$ W. M. Krogman Center for Research on Child Growth and Development at the University of Pennsylvania, Philadelphia,

PA, USA

${ }^{3}$ Drexel Food Lab, Drexel University, Philadelphia, PA, USA

${ }^{4}$ Department of Food and Hospitality Management, Drexel University, Philadelphia, PA, USA

${ }^{5}$ World Wildlife Fund, Washington DC, USA

Email: odonnell.tom@epa.gov

How to cite this paper: O'Donnell, T., Katz, S.H., Romey, A., Fulton, B., Croskey, L., Pearson, P. and Deutsch, J. (2021) Retail Seafood Waste Prevention: Reducing Retail and Consumer Fresh-Fish Waste by Cooking Directly from Frozen. Food and Nutrition Sciences, 12, 290-307.

https://doi.org/10.4236/fns.2021.123023

Received: January 15, 2021

Accepted: March 21, 2021

Published: March 24, 2021

Copyright $\odot 2021$ by author(s) and Scientific Research Publishing Inc. This work is licensed under the Creative Commons Attribution International License (CC BY 4.0).

http://creativecommons.org/licenses/by/4.0/

\begin{abstract}
More than $30 \%$ of fish caught from the world's oceans are never eaten by consumers adding a significant but unnecessary strain to the sustainability of global fisheries. Although a lot of this loss occurs at sea, in developed countries, a significant amount happens at retail stores and in households. People can help with this problem if they find and use new ways to interact with their retailers and with the way they store and cook seafood at home. Consumers can primarily purchase seafood that has never been frozen, was previously frozen, or is still frozen. Nearly all retail waste occurs when consumers do not buy seafood within a few days after it is in the unfrozen, display cases, forcing the stores to dispose of the fish in landfills or sewage plants. An estimated 220 million 4-ounce meal portions of the most popular seafood in the United States including shrimp, salmon, and cod meet this fate. This number can be reduced to the direct extent consumers can be persuaded to buy and cook from frozen. Retailers are motivated to sell more frozen seafood because profit margins are reported to be higher and labor and disposal costs are lower. Many stores also benefit from their brand's sustainability image, and contributions to corporate, national, and international waste reduction goals. Their challenge has been to educate and encourage consumers to choose frozen before fresh. Taste-testing evidence gathered in this study demon-
\end{abstract}


strated that consumers could adopt easy, new culinary skills to cook seafood from frozen that tastes just as good as what they are used to. Our studies also highlighted other consumer benefits, including: less fish handling required, simple preparation, easier meal planning, water savings, and higher levels of food safety. Based on these results it will be beneficial for stores to commit resources to consumer education and promote more frozen seafood sales in other ways that satisfy their management goals. Increasing consumer adoption can drive changes at the store level that will provide measurable contributions to seafood waste reduction.

\section{Keywords}

Seafood, Waste, Cooking, Fisheries, Consumers, Retail

\section{Introduction}

Globally, over a third of commercially caught fish is never eaten by people [1]. Much of this loss occurs during fishing when unwanted fish or parts of a fish catch are discarded back into the oceans. However, in developed countries much more is wasted at the retail store and household levels [2]. Reducing production discards and consumer waste is vital if the growing demand for fish is to be met in the most sustainable way possible, one that conserves each fishery, particularly wild fisheries that are so strained. Specifically, sixty percent of the world's fisheries are fully-fished to capacity and one-third are over-fished, according to estimates from the FAO [3]. The causes of consumer-stage fish loss and waste are the focus of this paper, emphasizing how retail stores manage their customers' purchasing options and behavior.

\section{Estimates of Seafood Retail Sales and Waste}

According to data compiled by the National Marine Fisheries Service, fish products in retail stores are predominately fresh and frozen. Approximately one-third of these products are sold in retail; the rest are sold in food service and restaurants (Table 1).

Fresh fish-or previously frozen fish-in retail stores are offered for sale either packed in ice or refrigerated in a glass or similar display case. Once in this condition, the fish quickly loses its freshness and appeal and after just two to three days it is usually discarded. It is unsafe to repurpose or refreeze the fish after this time, and even if it were, the loss of quality leaves the fish unsuitable for sale. Purveyors report that they won't sell any food that they would not eat themselves [4]. Trapped in this loop, the only practical place for two to three-day-old fish is in the trash or sink grinder. The desire of store owners and the appeal of shoppers to see abundant fish on display and to participate in the purchase choice results in lots of high-value seafood products being thrown away, over and over. 
Table 1. 2015 Value of fish products sold into the retail and restaurant market in the United States ([8], p. 61). Nine percent of these products are sold directly into industrial markets.

\begin{tabular}{ccc}
\hline Edible Fish & Value in Dollars & Percent of Total Retail \\
\hline Fresh and Frozen & $\$ 7,816,335,000$ & 84 \\
Canned & $\$ 1,302,131,000$ & 14 \\
Cured & $\$ 163,166,000$ & 2 \\
Total & $\$ 9,281,632,000$ & 100 \\
\hline
\end{tabular}

Shoppers have come to believe that never-frozen fish is the freshest; and therefore, the most healthy and tasty. While this might be true for fish that is caught and eaten the same day in coastal areas, it is not true for most commercially caught fish. For most of the world, the highest quality fish are actually those that were properly handled and then flash frozen as quickly as practical after being caught [5]. Vacuum sealed is also reported as a preferred method to preserve the quality of fish [6] [7]. Frozen fish in high quality packages retains the greatest degree of freshness. Fish-on-ice, even if packed quickly, begins to deteriorate. Therefore, a solution to the loss challenge includes changing consumer behavior and preferences towards buying frozen. This leads to important questions: 1) What type of seafood is lost, and how much of each type is lost? And 2) How much can behavior changes at retail hope to reverse this loss?

According to the National Marine Fisheries Service [8], the U.S. supply of edible, commercial finfish and shellfish in 2015 was 11.9 billion pounds. This is the whole fish weight, both edible and inedible parts. The portioned-out weight of fish fillets and steaks for restaurant and retail sales totaled a little more than 1.9 billion pounds. Popular Shellfish meat for the year was found to be 2.5 billion pounds. This equates to 17.6 billion, 4-ounce meal servings before any post-harvest food system losses. Most all of this fish was made up of the 19 most popular species (Table 2) - a clear target for beginning waste prevention actions. According to SeaFoodHealthFacts [9], one-third of seafood is purchased in retail. Shrimp leads the list for shellfish while salmon, cod, and pollock are the most popular finfish in the country. Other highly popular marine seafood products include hake, lobsters, crabs, oysters, scallops, and clams. Tilapia is the dominant freshwater fish. The popularity of these fish has remained consistent since at least 2006.

Most of these fish are imported, and programs to improve retail sale of these products by reducing waste would be helping improve the sustainability of $97 \%$ of international fisheries. Table 2 also shows the current sustainability status of each fish type. The Marine Stewardship Council (MSC) and Seafood Watch are two well-known rating agencies that match fishing pressure to the level of fish production by species. Reported ratings vary by where each species is caught; hence, ratings are by both fish type and the country providing the products for commercial markets. For example, cod is broadly certified by the MSC except 
from ocean sources exploited by Russia and Japan. This complicates the impact of fish loss reduction management plans, but having this data can inform target fish sources for organizations that want to make the most of their purchases on overall sustainability. Eleven of the nineteen species listed in Table 2 are either partially unrated or listed as "red-avoid" by the rating agencies. This is an environmental and ecological warning on the status of the fisheries that provides a large portion of the most popular fish in the United States. These ratings do not consider commercial fishing, including aquaculture and processing, that uses conscripted slave laborers, and other forms of worker abuse, an issue that is receiving increasing attention and concern as people become more aware of the extent of this practice and proof that United States retailers are purchasing seafood caught and or processed using labor practices that violate international law [10].

Table 2. Amount of the most popular fresh and frozen fish sold in the United States in 2015 ([8], p. 62, 98, 100, 101).

\begin{tabular}{|c|c|c|}
\hline Fish Fillets and Steaks & Total Pounds & 2018 Sustainability Rating* \\
\hline Alaskan and Atlantic Pollock & $462,028,000$ & MSC Certified $^{* *}$ \\
\hline Salmon, species & $95,120,000$ & Seafood Watch ${ }^{\star * \star}$ mostly farmed and red \\
\hline Cod & $63,973,000$ & MSC Certified but avoid Russian and Japanese sourced \\
\hline Hake & $26,004,000$ & Seafood Watch yellow but mostly unrated fishery \\
\hline Haddock & $13,917,000$ & MSC Certified \\
\hline Flounders & $11,517,000$ & Seafood Watch, mostly red \\
\hline Tilapia & $9,764,000$ & Seafood Watch yellow but $50 \%$ unrated \\
\hline Tuna species & $8,023,000$ & Seafood Watch, mostly red \\
\hline Halibut & $3,405,000$ & MSC Certified \\
\hline Dolphin fish & $3,167,000$ & Seafood Watch, mostly red \\
\hline Rockfishes & $2,572,000$ & Seafood Watch, green and yellow \\
\hline Perch, Atlantic and Pacific & $2,088,000$ & Seafood Watch, mostly green but Atlantic perch is not rated \\
\hline Swordfish & $2,052,000$ & Seafood Watch, mostly red \\
\hline Subtotal & $703,630,000$ & \\
\hline \multicolumn{3}{|l|}{ Shellfish } \\
\hline Shrimp, heads-off, all species & $1,796,684,000$ & Seafood Watch, mostly yellow \\
\hline Crab, meat King and Snow & $64,845,000$ & Seafood Watch, mostly yellow \\
\hline Clams, meat & $105,480,000$ & Seafood Watch, green or unrated \\
\hline Oysters, meat & $57,437,000$ & Seafood Watch, green \\
\hline Scallops, meat & $62,000,000$ & MSC Certified or unrated \\
\hline Lobster, tails and meat American and Spiny, & $58,707,000$ & American MSC Certified; Spiny, mostly red in Latin America \\
\hline Subtotal & $2,145,153,000$ & \\
\hline Total & $2,848,783,000$ & \\
\hline
\end{tabular}

${ }^{*}$ FishChoice, https://fishchoice.com/; ${ }^{* *}$ Marine Stewardship Council, https://www.msc.org/about-the-msc/what-is-the-msc; ${ }^{* * *}$ Monterey Bay Aquarium, https://www.seafoodwatch.org/3,248. 
Based on anecdotal information, there is a significant range in the proportion of fresh versus frozen product sales. This information is not publicly reported yet; however, there is some mention of proxies that can provide insight into the different product formats, for example product display areas in stores. Wegman's Food Markets [11] estimates that about a third of their seafood is displayed fresh. Other stores that were qualitatively evaluated for this research have indicated that 30 - 40 percent is fresh-unfrozen. There are not publicly available quantitative data about the amount of different fish species that are sold fresh versus frozen in retail. For example, pollack is very popular in frozen products but not so much in fresh displays in some stores. This is particularly meaningful because this fish is sold more than all the other listed, popular fish combined. Clams are another example because of its popularity as fresh, frozen, and canned. Future research should clarify the ratio of fresh versus frozen so measures to target loss prevention appropriate for the different formats can be efficiently deployed.

Table 3 assumes that one-third of the seafood supply goes on to retail stores, and second, that 45 percent of average fish sale capacity is fresh. Once in the retail market, $13 \%$ percent of fresh fish is thrown out [2], which represents an average of $9 \%$ of the total seafood supply [12]. Frozen waste is minimal and typically occurs due to a mechanical failure such as a broken freezer that causes a break in the cold chain or damaged packaging. Using the fish data from the previous table, 55 million pounds of the total reported weight of the most popular fresh fish from supermarkets is wasted each year, representing an equivalent of about 220 million, 4-ounce meal portions. Production data on species other than those listed can be found in Lowther and Liddel [8]. Both store, customer, and sustainability advocates can lead the way to resolving the important challenge of reducing this seafood waste.

Fresh shrimp sales at almost 600 million pounds comprise over $80 \%$ of the shellfish market. Sales of other popular shellfish sell in weights range from 19 34 million pounds. The story with finfish is similar because previously frozen or fresh pollock is at 152 million pounds and comprised about $65 \%$ of the market. In combination, the largest sellers, shrimp and pollock, represent $79 \%$ of the fish listed in Table 3. Reducing wastage of these two species alone would have an outsized impact on the entire seafood waste scenario in retail. In fact, if pollock and shrimp waste, distributed in retail as described in this report, were decreased by a bit less than two-thirds, the overall waste reduction would be $50 \%$ without improvements in any other loss fractions.

Information about lost sales revenue can be a stand-alone driver for managers to evaluate objective and subjective reasons for changing store waste prevention strategies. Table 4 summarizes the estimated dollar value of the fish species listed above. The estimates are based on average processed cost of each type of fish plus average retail markup percentages that were provided by the National Marine Fisheries Service [8]. Although the details of managing fish waste are not 
yet widely available, sufficient anecdotal feedback and reporting is emerging to start designing safe, store-based programs that may be incentivized by revenue and cost recovery. World Wildlife Fund [13] highlighted the following motivators: 1) lower disposal cost, 2) more sales revenue, 3) less handling time by store clerks, 4) new relationships and value-added opportunities with suppliers, and 5) happier customers that want to help reduce food waste.

Table 3. Estimated fresh fish wasted at USA retail (pounds, adapted from [6]).

\begin{tabular}{|c|c|c|c|}
\hline Fish & $\begin{array}{l}\text { Estimated Sold Fresh } \\
\text { and Frozen Retail in } \\
\text { Pounds }(33 \%)^{*}\end{array}$ & $\begin{array}{l}\text { Estimated Sold } \\
\text { Fresh in } \\
\text { Pounds }(45 \%) * *\end{array}$ & $\begin{array}{l}\text { Estimated Fresh } \\
\text { Retail Waste in } \\
\text { Pounds (13\%) }\end{array}$ \\
\hline $\begin{array}{c}\text { Alaskan and } \\
\text { Atlantic Pollock }\end{array}$ & $152,469,000$ & $68,611,000$ & $8,919,000$ \\
\hline Salmon, species & $31,390,000$ & $14,125,000$ & $1,836,000$ \\
\hline Cod & $21,110,000$ & $9,500,000$ & $1,235,000$ \\
\hline Hake & $8,581,000$ & $3,862,000$ & 502,000 \\
\hline Haddock & $4,593,000$ & $2,067,000$ & 269,000 \\
\hline Flounders & $3,801,000$ & $1,710,000$ & 222,000 \\
\hline Tilapia & $3,222,000$ & $1,450,000$ & 188,000 \\
\hline Tuna species & $2,648,000$ & $1,192,000$ & 155,000 \\
\hline Halibut & $1,124,000$ & 506,000 & 66,000 \\
\hline Dolphin fish & $1,045,000$ & 470,000 & 61,000 \\
\hline Rockfishes & 849,000 & 382,000 & 50,000 \\
\hline Perch, Atlantic and Pacific & 689,000 & 310,000 & 40,000 \\
\hline Swordfish & 677,000 & 305,000 & 40,000 \\
\hline Subtotal & $232,198,000$ & $104,490,000$ & $13,583,000$ \\
\hline \multicolumn{4}{|l|}{ Shellfish } \\
\hline Shrimp, heads-off, species & $592,906,000$ & $266,808,000$ & $34,685,000$ \\
\hline Crab, meat, King and Snow & $21,399,000$ & $9,630,000$ & $1,252,000$ \\
\hline Clams, meat, species & $34,808,000$ & $15,664,000$ & $2,036,000$ \\
\hline Oyster, meat & $18,954,000$ & $8,529,000$ & $1,109,000$ \\
\hline Scallop, meat & $20,460,000$ & $9,207,000$ & $1,197,000$ \\
\hline $\begin{array}{l}\text { Lobster, tails and meat, } \\
\text { American and Spiny }\end{array}$ & $19,373,000$ & $8,718,000$ & $1,133,000$ \\
\hline Subtotal & $707,900,000$ & $318,556,000$ & $41,412,000$ \\
\hline Total & $940,098,000$ & $136,046,000$ & $54,995,000$ \\
\hline
\end{tabular}

* Seafoodhealthfacts.org; ${ }^{* *}$ Benwick, 2018 and personal research; ${ }^{* \star}$ Love et al., 2015 , supplemental table S10. 
Table 4. Estimated 2015 cost of fresh fish losses in retail [8].

\begin{tabular}{|c|c|c|c|c|}
\hline Fish & $\begin{array}{l}\text { Estimated } \\
\text { Retail Loss in } \\
\text { Pounds }\end{array}$ & $\begin{array}{l}\text { Process Cost } \\
\text { for Fillets dollars } \\
\text { per Pound }\end{array}$ & $\begin{array}{l}\text { Processed } \\
\text { Cost, } \\
\text { Dollars }\end{array}$ & $\begin{array}{c}\text { Retail Cost, } \\
\text { Dollars } \\
\text { (markup 1.8\%*) }\end{array}$ \\
\hline Alaskan and Atlantic Pollock & $8,919,000$ & 1.36 & $12,102,000$ & $21,784,000$ \\
\hline Salmon, species & $1,836,000$ & 5.05 & $9,267,000$ & $16,680,000$ \\
\hline Cod & $1,235,000$ & 3.96 & $4,887,000$ & $8,796,000$ \\
\hline Hake & 502,000 & 1.30 & 653,000 & $1,175,000$ \\
\hline Haddock & 269,000 & 4.68 & $1,260,000$ & $2,268,000$ \\
\hline Flounders & 222,000 & 4.05 & 900,000 & $1,620,000$ \\
\hline Tilapia & 188,000 & 3.26 & 613,000 & $1,104,000$ \\
\hline Tuna species & 155,000 & 9.47 & $1,468,000$ & $2,643,000$ \\
\hline Halibut & 66,000 & 8.47 & 559,000 & $1,006,000$ \\
\hline Dolphin fish & 61,000 & 5.02 & 307,000 & 551,000 \\
\hline Rockfishes & 50,000 & 3.07 & 153,000 & 276,000 \\
\hline Perch, Atlantic and Pacific & 40,000 & 1.67 & 67,000 & 120,000 \\
\hline Swordfish & 40,000 & 8.75 & 350,000 & 630,000 \\
\hline \multicolumn{5}{|l|}{ Shellfish ${ }^{* *}$} \\
\hline Shrimp, heads-off, species & $34,685,000$ & 4.21 & $146,022,000$ & $262,840,000$ \\
\hline Crab, meat, King and Snow & $1,252,000$ & 5.97 & $7,469,000$ & $13,445,000$ \\
\hline $\begin{array}{l}\text { Clams, meat, species } \\
\text { (prices for canned variety) }\end{array}$ & $2,036,000$ & 1.12 & $2,289,000$ & $41,202,000$ \\
\hline $\begin{array}{l}\text { Oyster, meat (prices for } \\
\text { canned variety) }\end{array}$ & $1,109,000$ & 2.79 & $3,096,000$ & $5,573,000$ \\
\hline Scallop, meat & $1,197,000$ & 7.20 & $8,623,000$ & $15,521,000$ \\
\hline $\begin{array}{l}\text { Lobster, tails and meat, } \\
\text { American and Spiny }\end{array}$ & $1,133,000$ & 9.22 & $10,446,000$ & $18,803,000$ \\
\hline Total & & & & $416,037,000$ \\
\hline
\end{tabular}

*retail markup and value-added markup; ${ }^{* *}$ average import cost.

\section{Causes and Challenges of Seafood Waste}

Is it possible, and does it make sense to use resources for waste prevention and to reduce retail loss on the fresh fish display, or would the built-in years of inefficiency and loss be too strong of a barrier to overcome at a store level? After all, consumers will always prefer fresh over frozen fish to some degree. The Commission for Environmental Cooperation [14] recently completed an evaluation of food waste and loss in North America. Their approach included surveys and interviews related to conferences and workshops, all to gather the most current information. Awareness about the list of factors that cause food waste at the retail level has grown, and the CEC report highlights some that are particularly relevant to wastage of fresh fish, including: food safety concerns and management or marketing practices.

Food safety is on the minds of consumers, and in the case of seafood, concerns 
center around freshness and pollutants. Toxins in fish meat have been reported for some time; however, fisheries with low levels of pollutants of concern like lead, PCBs, and mercury are also being documented [14]. Customers can check and verify their purchases to take advantage of healthier fish supplies. Issues with freshness and microbial safety can be reduced by purchasing frozen and cooking according to the suggestions provided later in this paper. Management can be encouraged to modify their store practices by helping them understand some of the benefits that come from reducing fresh fish waste in favor of more frozen sales. Potential rewards include: increased sales, reduced waste disposal costs, improved corporate sustainability, and less pollution.

\section{Better Retail Practices for Sourcing and Selling Seafood}

The CEC report also pointed out different individuals that would have the most influence on changing marketing strategies and methods to reduce wastage. Included are store managers and employees, processors, distributors, and service providers that support both products and sales. There are sufficient detailed data and information available to begin to understand the loss factors and to suggest and target remedies. Seafood sales are going up in general, while fresh sales are increasing faster than frozen. This is the type of trend that leads to accelerating retail fish waste. It is possible that sales would increase even more if certain barriers were eliminated or lowered. Among these are people dislike for handling seafood and concerns for safety.

Encouraging more fish consumption for health reasons is at odds with consumer dislike for handling seafood. More inviting frozen-fish packaging that minimizes the tactile part of the culinary experience would help narrow the health-avoidance gap. Buyers already report that frozen offers more convenience and better storage options, both of which can lower waste at the consumer level. New frozen products are appearing in stores that minimize handling and offer recipes, sometimes with included ingredients. The availability of more types of frozen fish in new packaging then encourages consumers to buy frozen resulting in less retail waste. Stores benefit from more sales and less waste while consumers eat more nutritious fish.

Aquaculture production is increasing to fill the gap caused by a growing seafood demand that is outpacing global population growth and the capacity of wild-caught production. In total, constraints on the scalability of these systems and distribution limitations may still place a global deficit on available seafood as compared to recommended nutritional profiles for source proteins. Efforts to "sustainably source" wild caught seafood using standards like Marine Stewardship Council (MSC) and the Aquaculture Stewardship Council (ASC) have steadily increased among retailers and seafood purchasing groups. This trend is positive and one that must continue to accelerate and expose the limitations of wild seafood sources.

In order to achieve these goals, consumption patterns must be re-imagined and adjusted. Consumer focused pilots can address issues around consumer-generated seafood waste, such as frozen vs. fresh product, proper handling 
and preparation, more efficient packaging that increases merchandising appeal and retail sales and the importance of sustainable purchases. This purpose and approach is the focus of the research work that is reported in this paper with an emphasis on using the culinary arts to give people real experiences with handling, preparation, recipes and cooking from frozen.

Initial Consumer Attitudes and Research Objectives

In 2017, the Drexel Food Lab conducted consumer interviews and in-store consumer surveys $(n=100)$ at a busy nationally branded, locally owned supermarket on the border between the city and the suburbs of Philadelphia. Respondents were given a modest gift card to the store to thank them for their time. No personal data were collected, and the research was given a Letter of Determination from Drexel's Human Research Protection Program (IRB). The store was chosen for its ability to attract a diverse clientele of city-dwellers and suburbanites across a wide range of race, ethnicity, and socioeconomic status. The exploratory research reported here challenged the culinary and consumer preferences for fresh (previously frozen) seafood and asked if high-quality culinary standards can be achieved to the same or higher levels by preparing frozen seafood products directly from their frozen state, "cooking from frozen." This research is especially relevant in consumer and commercial settings, since the perception of "fresh" is skewed towards higher temperature storage, rather than a consumer reluctance to rate frozen as higher quality, even though by food safety, sustainability, and true freshness standards, frozen is superior (Figure 1). Among 100 consumers that were queried, the majority (52) responded that fresh fish was fresher. Our supposition is that the largest perception barrier to frozen seafood is a reluctance to view frozen seafood as desirable from a culinary standpoint. We also asked consumers what they thought about the quality of fresh versus frozen and much like the freshness response, 50 percent of consumers replied that fresh fish was higher quality (Figure 2). This high response rate further encouraged the research that followed our supposition because of the possibility of influencing consumers in ways that would significantly help to reduce wastage.

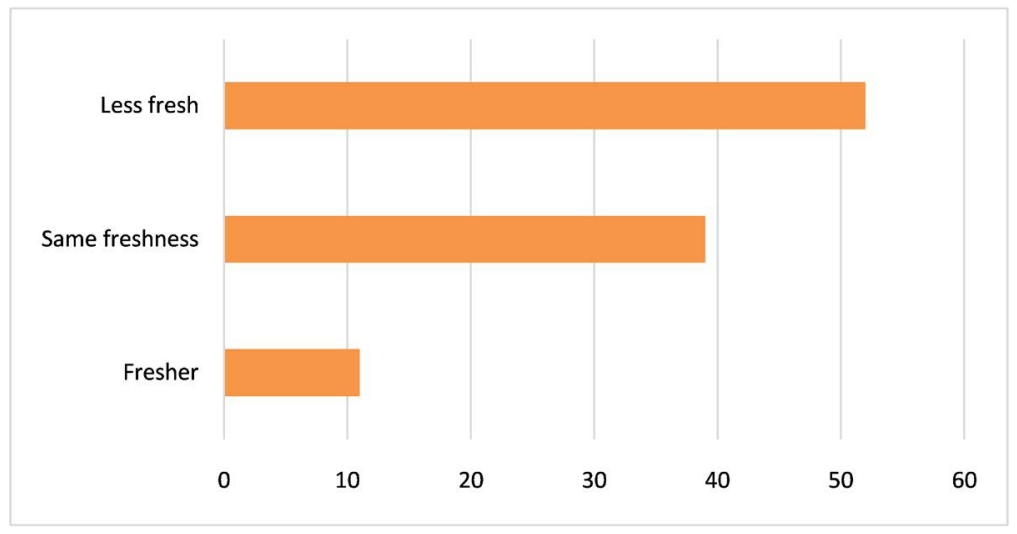

Figure 1. Consumer attitudes about the freshness of frozen fish compared to fish from counter. 


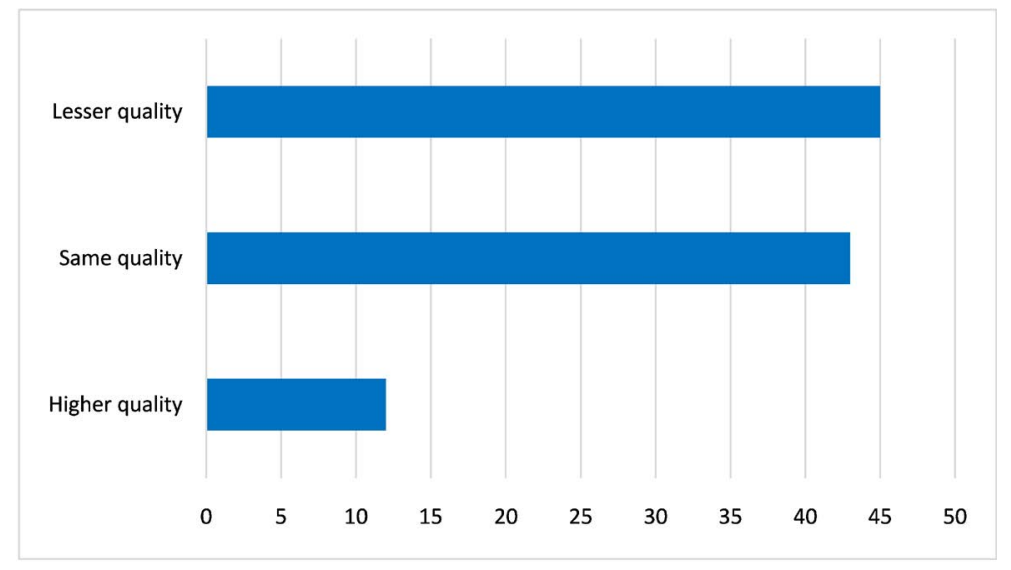

Figure 2. Consumer attitudes about the quality of frozen fish compared to fish from counter.

Food safety plays a large role in behaviors and patterns. Once defrosted, most fish cannot be safely re-frozen and typically goes to waste if not purchased or prepared. Defrosted fish also has a higher likelihood of being wasted at the household level. Purchased fish sits in a refrigerator and, as dinner plans change, it may be discarded without being cooked or re-frozen by the consumer after increased opportunity for microbial growth and oxidative rancidity (resulting in the characteristic fishy smell) from the defrosted stage [15].

Consumers shared that the step of defrosting frozen seafood is a deterrent to purchasing it. Package instructions typically indicate that the fish or seafood must be thawed under refrigeration for several hours or under cold running water (further wasteful from a sustainability standpoint). Consumers report hurdles associated with either of these scenarios including: not being organized enough to plan dinner days in advance and move seafood from freezer to refrigerator; not being patient enough to wait for defrosting under water; not wanting to waste water; and changing plans resulting in not getting around to cooking the defrosted seafood as intended. In addition, some consumers share insecurities with regard to proper handling and cooking of seafood, especially finfish, as well as expressing displeasure in having to handle raw fish during cooking. In short, consumers report wanting to eat more seafood but find the hurdles to buying and handling the products to be deterrents.

Inspired by knowledge of loss rates in the retail seafood supply chains, Drexel Food Lab principals and students investigated if it would be possible to cook fish directly from its frozen state at high culinary quality, the way one cooks a frozen hamburger patty. With some caveats, the answer is "yes" (Figure 3). Fifty-five of 100 respondents were positive about the idea of cooking from frozen in theory.

Research objectives evolved and expanded to gather real consumer feedback and see how the Cook-from-Frozen recipes and new knowledge collected during the investigation can influence sales. In collaboration with the supermarket, we obtained retail data and piloted a variety of interventions in stores. They confirm extensive losses and little conversion to prepared product at the fish counter and 


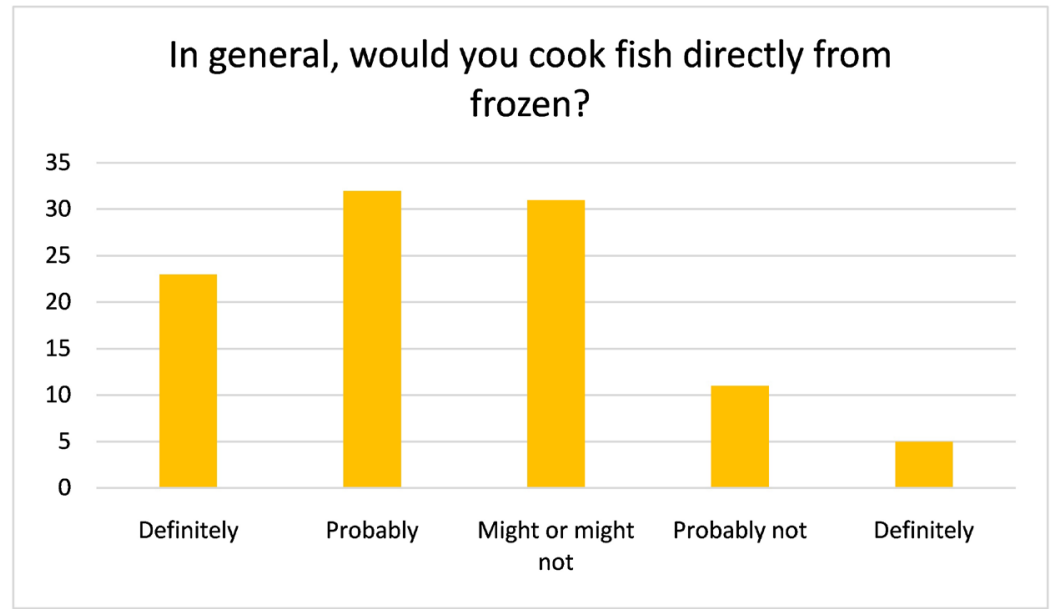

Figure 3. Consumer attitude about cooking from frozen if quality was certain (post tasting).

further confirmed that the stores have better profit margins on frozen fish (both in terms of gross margins on the products themselves and reduced staffing and loss management from waste). With these multiple benefits the store welcomed the opportunity to encourage a shift in sales to frozen seafood.

Our taste testing and marketing research had several specific parts:

- Complete recipe development and testing of Cook-from-Frozen recipes

- Engage a graphic designer for the layout and printing of customer marketing materials

- Taste tests of recipes at supermarkets

- Collect consumer acceptance feedback on the appeal of buying frozen fish as well as the success of the recipes.

\section{Methodology for Recipe Development and Taste-Testing}

In Spring 2017, several types of fresh and frozen seafood items were selected for evaluation based on sales priorities and sustainability-certified products provided by the retailer. The primary items were shrimp, salmon, and tilapia as proxies for a variety of related crustaceans, fatty fish, and lean fish. Culinary experiments found that methods like roasting, poaching, and baking en papillote were particularly effective, while frying and grilling resulted in difficulty achieving thorough cooking directly from frozen. Recipes and cooking recommendations were made (see below) for each fish type.

\section{Communication}

Following recipe testing, a consumer education brochure was designed for distribution in the customer's frozen seafood section of the supermarket. The brochure contained recipes for cook-from-frozen seafood, an explanation of the sustainability, food safety and convenience aspects of cook-from-frozen seafood, a description of the partnership/project, and an explanation of the company's overall work on sustainable seafood (recipe examples and the brochure are included in the supplemental materials).

\section{Consumer feedback}


The suburban Philadelphia store location that serves city and suburban customers was used to launch four weekly tasting sessions. Patrons had the opportunity to taste a Cook-from-Frozen fish sample (a tilapia curry or roasted salmon) and provide feedback via a one-minute survey. Shoppers were asked if they would like to sample a Cook-from-Frozen fish dish. Each participant was given a $\$ 5$ in-store gift card. Approximately 250 samples were served weekly and those who completed the tasting were asked if they would like to complete the survey as well. A 10\% response rate yielded 100 completed surveys. Recipes and brochure handouts were available to everyone. Highlights of survey results are shown in Figure 4. About 34 percent of participants indicated that they would try this Cook-from-Frozen technique after trying the dish. Only 7 percent said they would cook from frozen before their tasting experience.

\section{Summary and Conclusion}

A 2017 report from IRi shows that fresh seafood has seen marked increases in consumer interest [16]. Increasing customer demands for fresh product are often derived from a perception that thawed fish is "fresh" simply because it most closely resembles the state of fish pulled immediately from the water. Once a human intervention is imposed (i.e., fish is frozen), consumers perceive that the fish is no longer "fresh". In reality, given the distances and the complexities of our fresh food supply chains, delivering truly fresh fish under these visually appealing circumstances is extremely costly and reduces the shelf-life of the product.

Since it is standard practice for many retailers to thaw previously frozen fish for display, we can conclude that thawing fish to display it as "fresh" is merely a marketing strategy to satisfy consumer visual impulses to see fish that was just pulled out of the river or ocean. The display life of this form of seafood is short. Loss is accepted in retail systems as a price of doing business, since it's assumed and seldom challenged that customers want to see thawed fish. Furthermore, loss rates are rarely if ever made public and are guarded under strict business confidentiality. Anecdotally, loss rates are typically estimated between $8 \%-20 \%$ of total sales at most seafood counters.

This investigation tested the proposition that, with proper consumer education, frozen fish can be merchandised as high-quality and that preparation can be just as convenient as thawed fish from the seafood counter. If in-store marketing campaigns can sell the benefits of frozen and alternative packaging models, and if these new products can maintain or even increase seafood sales, it becomes a multi-faceted win for retailers: increased sales, less in-store shrink (increased margin), happy customers, and less stress on the environment.

From a culinary perspective, Cook-from-Frozen remains a promising cooking method, offering consumers a more convenient, safer, and more sustainable solution than buying fresh-from-frozen or defrosting at home. Quality of finished dishes was on par with fresh. For the typical consumer, cook-from-frozen seafood is an appealing alternative. Benefits include: 
- Are you more likely to buy frozen fish and cook it directly from frozen after participating in the demo?
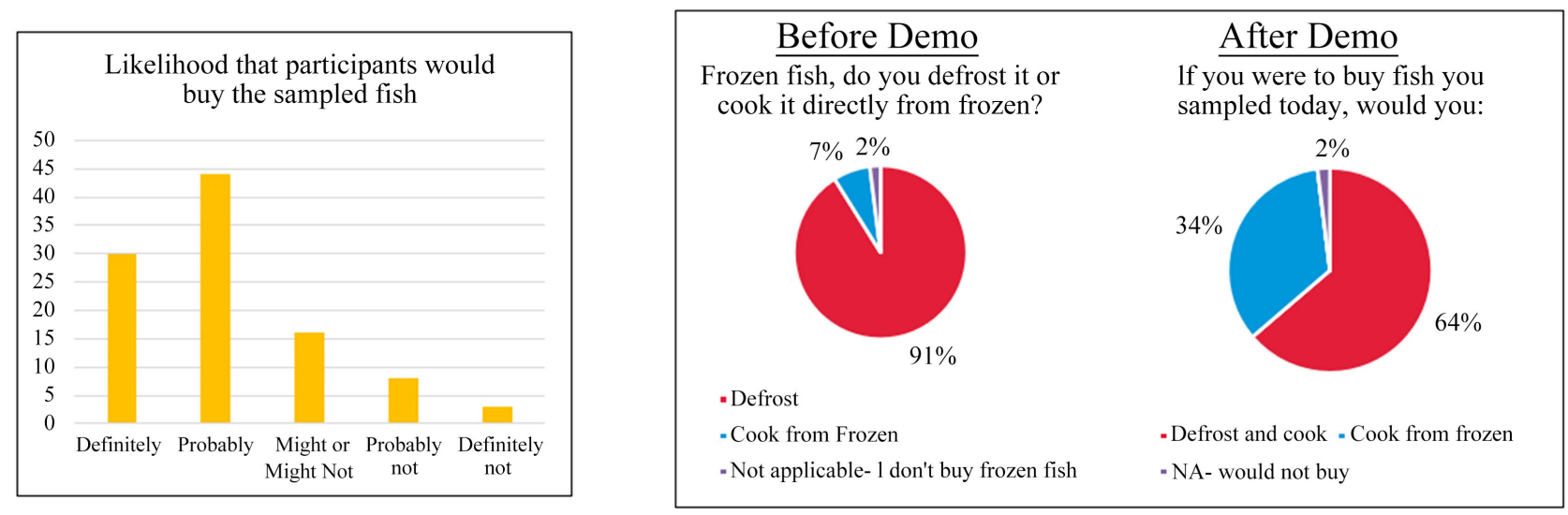

Figure 4. Summary of consumer feedback after participating in Cook-from-Frozen in-store tasting sessions.

- Limited handling required

- Simple preparation

- Makes advanced meal planning easier

- Saves water in defrosting

- Preserves cold chain at zero degrees F until the point of cooking.

Benefits to retailers include:

- Reduced personnel time and training needs

- Reduced cost of food loss

- Reduced store footprint (receiving, prep area and display)

- Easy recipe and cooking promotion opportunity for customers

This research has reached the following important conclusions: 1) Consumers perceive the thawed seafood is more fresh than frozen seafood. It is not. 2) Cooking demonstrations can teach consumers how to successfully cook from frozen. More consumer education in this area is useful and necessary. 3) Selling frozen product reduces seafood losses. Retailers benefit financially.

In summary, maintaining the current seafood merchandising system to appeal to consumer's actually increases waste and does not contribute to sustainable fish stocks. Educating consumers about how to purchase and cook-from-frozen is an incremental component of seafood waste reduction that directly enhances sustainable fisheries and builds consumer awareness of economic and healthy tools they can use to expand the potential of seafood to meet nutritional requirements.

\section{Disclaimer}

Any views expressed in this report do not necessarily represent those of the United States government or the Environmental Protection Agency. Mention of trade names or commercial products does not constitute endorsement or recommendation for use. 


\section{Conflicts of Interest}

The authors declare no conflicts of interest regarding the publication of this paper.

\section{References}

[1] Food and Agriculture Organization of the United Nations (2017) Reduction of Fish Food Loss and Waste. http://www.fao.org/fileadmin/user upload/COFI/FishTrade/uploads/6e.pdf

[2] Love, D.C., Fry, J.P., Milli, M.C. and Neff, R.A. (2015) Wasted Seafood in the United States: Quantifying Loss from Production to Consumption and Moving toward Solutions. Global Environmental Change, 35, 116-124.

https://doi.org/10.1016/j.gloenvcha.2015.08.013

[3] Food and Agriculture Organization of the United Nations (2018) The State of World Fisheries and Aquaculture 2018 in Brief. Food and Agriculture Organization of the United Nations, Rome, 227 p.

[4] Cabrini University (n.d.) Serving Food Solutions.

http://servingfoodsolutions.com/the-problem/food-waste/environmental-effect/foo d-waste-copy/

[5] Ecotrust (2017) A Fresh Look at Frozen Fish Expanding Market Opportunities for Community Fishermen.

https://ecotrust.org/publication/a-fresh-look-at-frozen-fish/

[6] Shaw, H. (2019) Before You Buy Seafood at a Supermarket. The Spruce Eats. https://www.thespruceeats.com/buying-seafood-at-a-supermarket-1300630

[7] Science Direct (n.d.) Frozen Fish. https://www.sciencedirect.com/topics/food-science/frozen-fish

[8] Lowther, A. and Liddel, M. (2016) Fisheries of the United States 2015. 151 p. https://www.st.nmfs.noaa.gov/Assets/commercial/fus/fus15/documents/FUS2015.p df

[9] Seafood Health Facts (2017) Overview of the Seafood Industry. https://www.seafoodhealthfacts.org/seafood-choices/overview-seafood-industry

[10] Grant, J. (2019) Slavery in the Seafood Industry. https://www.sustainalytics.com/esg-blog/slavery-forced-labor-seafood-industry/

[11] Benwick, B.S. (2018) Buying Frozen Fish Isn't What It Used to Be. Here's What You Need to Know, Washington Post. https://tinyurl.com/y4fz897k

[12] Buzby, J.C., Wells, H.F. and Hyman, J. (2014) The Estimated Amount, Value, and Calories of Postharvest Food Losses at the Retail and Consumer Levels in the United States. EIB-121, U.S. Department of Agriculture, Economic Research Service, Washington DC. https://dx.doi.org/10.2139/ssrn.2501659

[13] Stone, A. (2018) Out of the Sea, Waste I Could Be. https://www.worldwildlife.org/blogs/sustainability-works/posts/out-of-the-sea-wast e-i-could-be

[14] Commission for Environmental Cooperation (2018) Food Loss and Waste Reports. http://www3.cec.org/fw/food-waste-reports/

[15] Clay, J. (2017) Leaving Value on the Boat. http://www.brinknews.com/leaving-value-on-the-boat/

[16] IRi (2017) 2017 Top Trends in Fresh Foods. Food Marketing Institute, Washington 
DC.

https://www.fmi.org/docs/default-source/default-document-library/top-trends-in-fr esh poviri2017.pdf?.sfvrsn $=4 \mathrm{ad} 97 \mathrm{c} 6 \mathrm{e} \quad 2$ 


\section{Supplemental Materials}

\section{Sample recipe:}

Roasted Salmon Sheet Tray Dinner with Soy Ginger Sauce by Alexandra Romey

Serves: 4

2 tablespoons olive oil

4 ShopRite Preferred Brand frozen salmon fillets

$1 / 4$ cup soy sauce

2 tablespoons sesame oil

1 tablespoon minced ginger

1 tablespoon honey

1 pound snap peas

8 ounces mushrooms

2 bell peppers, chopped

Salt and pepper to taste

1) Preheat oven to 350 degrees Fahrenheit.

2) On a baking sheet tray, drizzle olive oil. Place salmon on one section of the tray and roast for 20 minutes.

3) Meanwhile, in a small bowl, add soy sauce, sesame oil, ginger and honey. Stir.

4) Once the salmon is partially cooked, add snap peas to a section of the tray, mushrooms to another, and peppers in remaining area. Drizzle soy ginger sauce over salmon and vegetables.

5) Return tray to oven and cook for 20 - 25 minutes, or until vegetables are tender and salmon is cooked through.

6) Serve salmon, snap peas, mushrooms and peppers with brown rice.

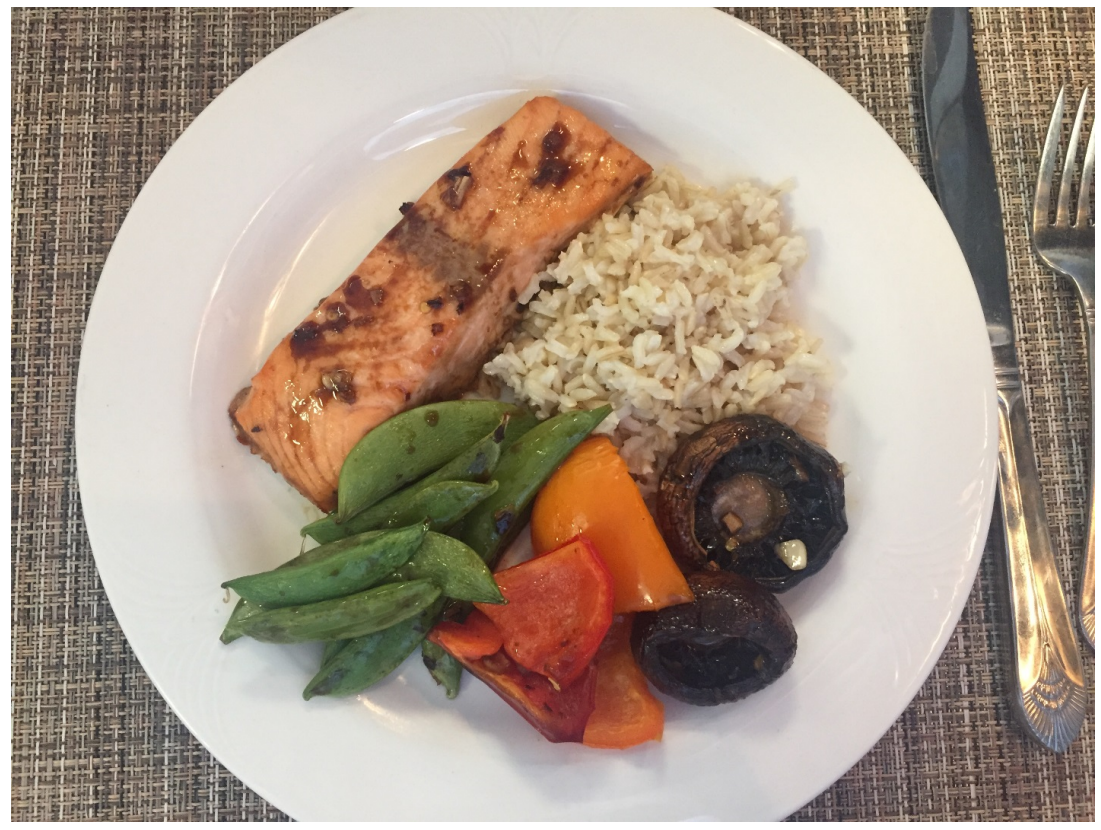




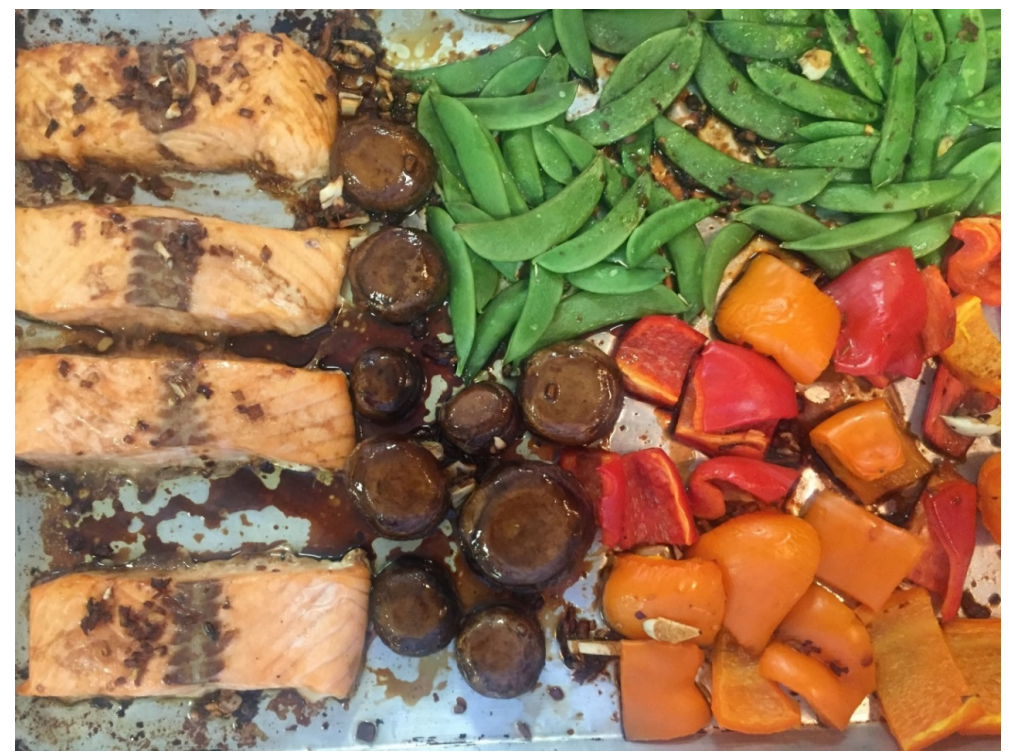

\begin{tabular}{|c|c|}
\hline $\begin{array}{r}\text { Nutrition F } \\
\begin{array}{r}1 \text { Fille } \\
\text { facts are } f\end{array} \\
\text { Serving size }\end{array}$ & $\begin{array}{l}\text { acts } \\
\text { (nutrition } \\
\text { or cooked } \\
\text { fish only) }\end{array}$ \\
\hline $\begin{array}{l}\text { Amount Per Serving } \\
\text { Calories }\end{array}$ & 260 \\
\hline & \% Daily Value" \\
\hline Total Fat 13g & $17 \%$ \\
\hline Satura & $10 \%$ \\
\hline & \\
\hline rated Fat 6g & \\
\hline Monoun & \\
\hline Cholester & $23 \%$ \\
\hline Sodium & $18 \%$ \\
\hline Total Ca & \\
\hline Dietary & \\
\hline Total Su & \\
\hline $5 \mathrm{~g}$ Added Sugars & $10 \%$ \\
\hline Protein $28 \mathrm{~g}$ & $56 \%$ \\
\hline $\mathrm{amin} D 14.4 \mathrm{mcg}$ & $70 \%$ \\
\hline & \\
\hline & $15 \%$ \\
\hline Potassium 470mg & $10 \%$ \\
\hline & \\
\hline
\end{tabular}

Consumer Educational Brochure

Promotional $\mathrm{Brc}$ Developed in Partnership with Brown's and Wakefern
ILAPIA CURRY

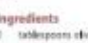

\section{YY}

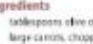
tistarim dispet

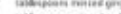

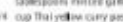

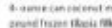
Method 1) ha lergepos over medum teat war

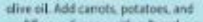
int cos for atoon 10 minutes, inall rejetiatle begin to wofer.

a) Med callons ginger, gantc, and cary paite. Sert to contion and

1) Ned coconat rik atd 3 quated of wate.

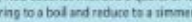
Caik bre abost 10 minuet.

4 Abs thple and timent for arethe 30

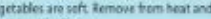
Fimes with cibution
Dear Customers,

Shoppite is dedicated to color generations to come.

Our seadood supplier, Wakefert Food Comp, has partnered whin

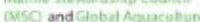
Since (CAA) to ensure that our wild-cavghe and farm-raised ood are sourced firom certified, sustainable fisheries and tarms.

Contact Us

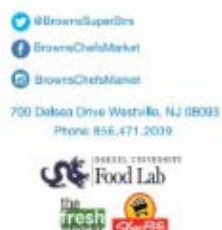

thet

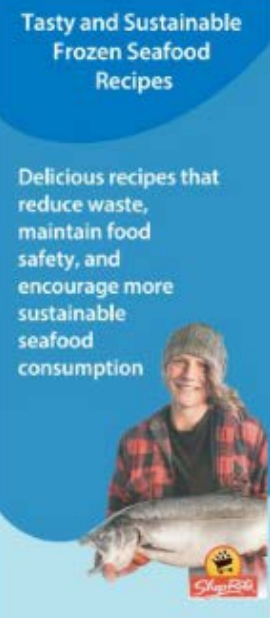

Tasty and Sustainable zen Seafood Recipes

Delicious recipes that

safety, and

encourage more

seafood 


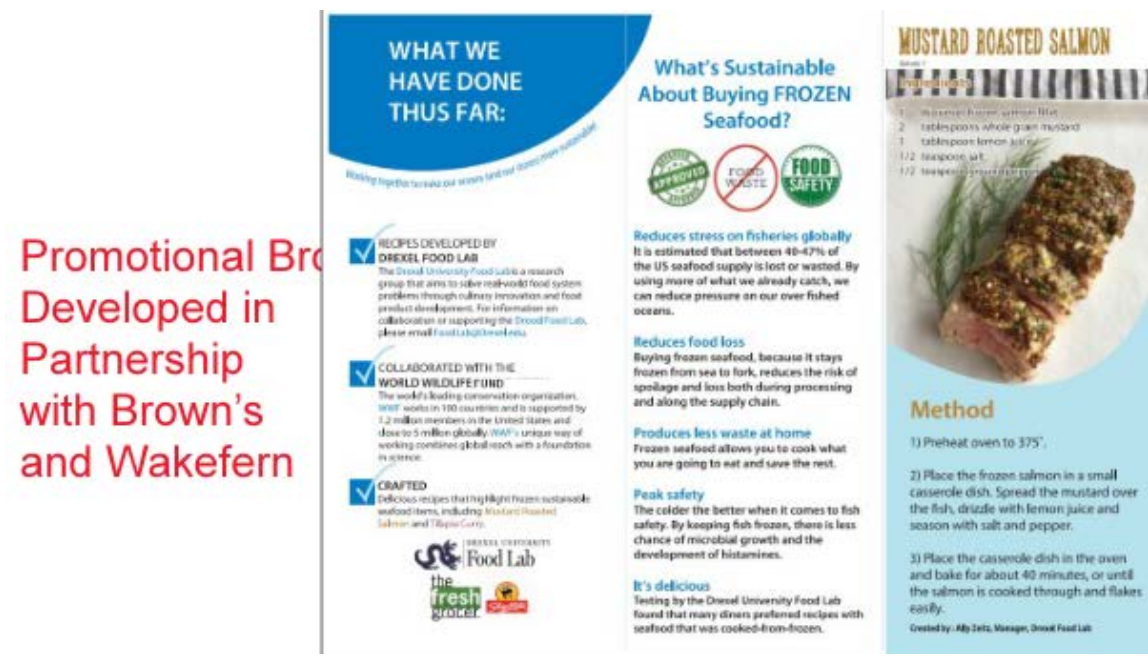

